\title{
Production and purification of antibody by immunizing rabbit with rice tungro bacilliform and rice tungro spherical viruses
}

\begin{abstract}
Rice tungro disease is the major disease caused by infection with the rice tungro bacilliform virus (RTBV) and rice tungro spherical virus (RTSV). In this study, New Zealand White rabbits were immunized with pure viruses for the production of antibodies against both species. The production of polyclonal antibodies against Tungro viral disease using ammonium sulfate precipitation and a protein A affinity column and their assessment are described. Two peaks were found from the protein A affinity column. Peak 1 represents the unbound compounds from the extracted serum and peak 2 represents antibody that bound to protein A, which was eluted using elution buffer. Peak 2 was collected for antibody titration. The amount of pure antibody in the titers was quantified by enzyme-linked immunosorbent assay (ELISA) to capture the tungro viruses. Antibody titer was analyzed by the ELISA method. For anti-RTBV, $1.696 \mathrm{mg} / \mathrm{mL}$ was highest at the second bleed and anti-RTSV was $2.3225 \mathrm{mg} / \mathrm{mL}$ was highest at the first bleed. These antibodies detected the tungro viral disease well and proved to be a potential probe for the detection of rice tungro disease.
\end{abstract}

Keyword: Tungro disease; Rice tungro bacilliform virus; Rice tungro spherical virus; Antibody titer; Enzyme-linked immunosorbent assay 